\title{
Condições de trabalho e sintomas relacionados à saúde de catadores de materiais recicláveis em Curitiba
}

\section{Work conditions and health symptoms of ragickers in Curitiba}

\author{
Maria do Carmo Baracho de Alencar ${ }^{1}$, Cintia Carolini Orlandini \\ Cardoso $^{2}$, Maria Cristina Antunes ${ }^{3}$
}

\begin{abstract}
ALENCAR, M. do C. B. de.; CARDOSO, C. C. O.; ANTUNES, M. C. Condições de trabalho e sintomas relacionados à saúde de catadores de materiais recicláveis em Curitiba. Rev. Ter. Ocup. Univ. São Paulo, v. 20, n. 1, p. 36-42, jan./abr. 2009.
\end{abstract}

\begin{abstract}
RESUMO: O objetivo desta pesquisa foi o de caracterizar as condições de trabalho e investigar sintomas relacionados à saúde de catadores de materiais recicláveis, vinculados a Instituições de coletas na cidade de Curitiba-PR. A metodologia consistiu de duas etapas: seleção de duas instituições de coletas e entrevistas junto aos proprietários acerca do trabalho dos catadores; e seleção de 22 catadores, sendo 11 de cada Instituição para a análise das tarefas e atividades de trabalho, com embasamento na Ergonomia (Guérin et al., 1994); aplicação de um questionário contendo dados demográficos, sócio-econômicos, aspectos relacionados à saúde com sintomas de frequência semanal no último mês (baseados no UCU Stress Model Questionnaire), e questões relacionadas à como se sentem no trabalho (ansiosos, desamparados, frustados, humilhados). Dos entrevistados $72,7 \%$ eram do gênero masculino e $27,3 \%$ do gênero feminino. Os resultados indicaram que há uma precarização nas condições de trabalho nas categorias: perfil sócio-demográfico, condições físicas, condições ambientais, medos e receios, e processos do trabalho. Observou-se a presença de dores músculo-esqueléticas em 90,9\% e cansaço físico em $95,5 \%$ dos entrevistados. Outros sintomas encontrados: $81,8 \%$ com dores de cabeça; $27,3 \%$ com erupções cutâneas, $45,5 \%$ com indigestão; $63,6 \%$ com oscilação de humor; $45,5 \%$ com dificuldade de concentração; $27,3 \%$ com insônia; entre outros. Também foram relatados: ansiedade (68,2\%), desamparo (54,5\%), frustração $(59,1 \%)$, e humilhação $(40,9 \%)$ entre os entrevistados. Concluiu-se que esta atividade pode afetar a saúde tanto física quanto mental dos trabalhadores, havendo necessidade de Políticas Públicas que promovam melhorias nas condições de trabalho.
\end{abstract}

PALAVRAS CHAVE: Catadores. Condições de trabalho. Saúde ocupacional.

\footnotetext{
${ }^{1}$ Professora do curso de Terapia Ocupacional da Universidade Federal de São Paulo.

${ }^{2}$ Acadêmica do curso de Terapia Ocupacional da Universidade Tuiuti do Paraná.

${ }^{3}$ Professora do Departamento de Psicologia da Universidade Tuiuti do Paraná.

Endereço para correspondência: Maria do Carmo Baracho de Alencar. Rua Prof. Torres Homem, 570. Bairro Aparecida. 11.025021 Santos, SP. E-mail: belinha.alencar1@gmail.com
} 


\section{INTRODUÇÃO}

$\mathrm{O}$ processo de globalização econômica tem causado muitas mudanças no mundo do trabalho, ocasionando consequentemente mudanças no perfil da classe trabalhadora; entre as mudanças, está o fato de as empresas estarem exigindo educação mínima de primeiro ou segundo grau completos, para determinadas funções; o que dificulta para aqueles sem o grau de instrução mínimo exigido, o acesso a um emprego com carteira assinada. Camargo e Reis (2006) citam que a taxa de desemprego é crescente à medida que diminui os anos de estudo. Este fato pode afetar o aumento no número de pessoas que buscam a atividade de catador de materiais recicláveis nas ruas, como citam Medeiros e Macêdo (2006).

Com o intuito de organizar a classe, Cooperativas foram formadas, e houve uma mobilização nacional para o reconhecimento formal da profissão, que ocorreu em 2002. Segundo a Classificação Brasileira de Ocupações (CBO), se encontra a profissão "catador de material reciclável" sob o código 5192-05. Dentro das descrições das atividades pela CBO: "catam, selecionam e vendem materiais recicláveis como papel, papelão e vidro, bem como materiais ferrosos e não ferrosos e outros materiais não reaproveitados". Enquanto parte da população descarta o material que não utiliza mais, o lixo, os catadores visam transformar esse material em uma forma de sustento, de sobrevivência. Uma das características desse trabalho, é que está diretamente relacionado ao ambiente em que o mesmo é realizado (pelas ruas), estando sujeito às situações climáticas, à violência, trânsito, entre outros. A atividade do catador exige um trabalho exaustivo, percorrendo quilômetros por dia para aqueles que empurram carrinhos, e é realizada em condições precárias. Para Medeiros e Macêdo (2006) a precariedade no trabalho do catador se refere ao trabalho mal remunerado, pouco reconhecido, e que provoca um sentimento de inutilidade do trabalhador.

O trabalho é uma atividade humana que terá um significado, e a importância desse fato está na construção da identidade do sujeito e na sua socialização (GUÉRIN et al., 1997; MORIN, 2004). Heloani e Lancman (2004) citam que "o trabalho possui uma função psíquica enquanto um dos grandes alicerces da constituição do sujeito e de sua rede de significados". Para Morin (2004), dentro da significância do trabalho, estão: o valor que o sujeito atribui ao trabalho, as suas representações e a importância que o mesmo tem para o sujeito. Condições adversas no trabalho tendem a gerar sobrecargars no aparelho psíquico e físico. Segundo Cruz
(2004) a análise do trabalho é uma análise das consequências da atividade do trabalhador, e são consideradas ônus da atividade aquelas listadas comumente como "carga de trabalho". Diversas situações de trabalho podem gerar efeitos psicológicos ao trabalhador (reação ao agente estressor), e o mesmo pode manifestar de diversas formas, seja em comportamentos, ou através de alterações psicológicas ou fisiológicas. Vários trabalhos colocam em risco a saúde mental e o trabalho de catadores de materiais recicláveis se enquadra entre eles; em um estudo de Silva et al. (2006) ser catador de materiais recicláveis expõe o trabalhador a ter 20,0\% mais chance de ter distúrbios psíquicos menores. Segundo o WHO (2000) são características estressoras no trabalho: pouco salário, pobre status, carreira incerta, insegurança no emprego, pouco valor social no trabalho, entre outros.

Cabe mencionar que vários são os modelos teóricos que analisam e investigam aspectos relacionados à saúde mental e trabalho, entre eles: as teorias do Estresse, a Psicodinâmica do Trabalho, e a Ergonomia (FERNANDES et al., 2006).

Em relação ao trabalho dos catadores, a coleta ainda expõe os catadores de lixo a alguns riscos à saúde. Para Ferreira e Anjos (2001) os catadores ao remexerem em resíduos vazados à procura de materiais recicláveis, estão expostos à contaminação presentes nos resíduos, além dos riscos à integridade física pelo manuseio. Para os autores objetos perfurantes e cortantes são os principais agentes de risco. Em relação à saúde ainda, Porto et al. (2004) em seu estudo com catadores de materiais recicláveis, encontrou: $31,1 \%$ com hipertensão arterial, $20,2 \%$ com varizes, $13,8 \%$ com problemas osteoarticulares, $9,6 \%$ com problemas cardíacos, $4,2 \%$ com asma e $3,2 \%$ com diabete. Outros estudos relacionados aos catadores apontam condições subumanas de trabalho (Leal et al., 2002), e associações quanto a uma configuração de rebaixamento na posição social, caracterizando uma configuração de exclusão social (MEDEIROS; MACÊDO, 2006). Segundo Lopes (2006) a concepção "exclusão social" se caracteriza por fenômenos: desemprego estrutural, precarização das condições de trabalho, desqualificação profissional, falta de acesso aos serviços de saúde, desagregação identitária, entre outros. Sob a exclusão social, Velloso (2005) cita que os catadores são vistos como marginais à sociedade, e mesmo ao se organizarem em associações ou cooperativas ainda sofrem discriminações.

Apesar da formação de Cooperativas, para auxiliar na organização do trabalho, existem Instituições "paralelas" de coletas na cidade de Curitiba, com regras próprias, onde alguns catadores são vinculados sem vínculo empregatício. Essas Instituições compram os materiais recicláveis dos 
catadores e repassam para as empresas de reciclagem.

O objetivo desse estudo, foi investigar as condições de trabalho de catadores de materiais recicláveis vinculados a duas Instituições de coletas, e investigar a presença de alguns sintomas relacionados à saúde dos trabalhadores, na cidade de Curitiba-PR.

\section{MATERIAIS E MÉTODOS}

O estudo é descritivo e exploratório, e consistiu de duas etapas.

Inicialmente foram selecionadas aleatoriamente duas Instituições de coletas (não Cooperativas), de vínculos com catadores de materiais recicláveis, dado obtido através de entrevistas abertas e informais entre catadores que trabalhavam nas ruas da cidade. Foi elaborado um Termo de Consentimento livre e esclarecido, apresentado e autorizado, e posteriormente entrevistado os responsáveis pelas instituições. Para essas entrevistas, foi elaborado um questionário contendo questões: se era particular; como a Instituição se mantinha (sustento); há quanto tempo existia; qual era a finalidade; como era organizado o funcionamento da instituição; vantagens de ser vinculado à ela; como os catadores chegavam até a instituição; se haviam critérios para a seleção dos catadores; como era realizada a remuneração para o catador; como era organizada a entrega de materiais coletados; como eram direcionados os locais de coleta para cada catador; se os instrumentos de locomoção dos catadores eram fornecidos pela instituição; quais eram as dificuldades gerais encontradas pela instituição. Para os resultados, as instituições serão descritas em Instituição "A" e Instituição "B".

Posteriormente foram realizadas as análises das tarefas e atividades de trabalho dos catadores de materiais recicláveis, com base na Ergonomia (GUÉRIN et al., 1997). Foram selecionados aleatoriamente 22 catadores de lixo, de ambos os sexos, maiores de 18 anos, sendo 11 catadores de lixo vinculados à cada Instituição. Também foi elaborado e apresentado um Termo de Consentimento, e participaram da pesquisa aqueles que estavam de acordo. Buscou-se levantar e descrever as tarefas dos catadores de materiais recicláveis nas duas instituições, descrição dos locais de trabalho, vínculos existentes no trabalho, aspectos da organização do trabalho, entre outros. Para complemento aos dados foi elaborado um questionário contendo dados gerais individuais (idade, gênero, escolaridade), e outros: condições de moradia (se própria, alugada, de favor, ou outra), filhos (quantidade), renda mensal obtida com o trabalho, e na última parte questões sobre aspectos relacionados à saúde, sintomas estressores nos últimos 30 dias (sintomas obtidos a partir do instrumento UCU Model Stress Questionnaire, 1990); presença ou não de dor músculo-esquelética nos últimos 30 dias, e região (com respostas: nunca, às vezes, e frequentemente), e como se sentem (ansiosos, desamparados, frustrados, humilhados), com respostas: nunca, às vezes, freqüentemente. Esses questionários foram aplicados sob forma de entrevista, que duraram em média 55 minutos, com espaço reservado para as mesmas.

As observações das atividades dos catadores, ocorreram durante um período de dois meses (novembro e dezembro), sendo as observações realizadas por um período médio de duas horas, três vezes na semana; incluindo o acompanhamento das atividades nas ruas da cidade. Também foram registrados comentários dos trabalhadores durante as atividades, com registros através de papel e caneta, e registros de outros relatos (falas) espontaneamente obtidos, e outros dados relevantes ao estudo.

Este projeto foi realizado em 2007, e teve a aprovação do Comitê de Ética em Pesquisa da Universidade Tuiuti do Paraná (n.113/07), e participação de aluna do curso de Terapia Ocupacional, em Iniciação Científica.

\section{RESULTADOS E DISCUSSÃO}

Os resultados serão apresentados por aspecto analisado.

\section{As Instituições de coletas}

Foram entrevistados dois proprietários de Instituições de coletas particulares, um de cada Instituição, aqui descritas em Instituição "A" e "B", cujos dados gerais estão demonstrados na Tabela 1.

Para ser vinculado às Instituições o trabalhador deveria ter idade igual ou superior à 18 anos. Em análise comparativa quanto às duas Instituições, a Instituição "B", não oferecia local para a separação dos materiais, e ainda cobrava uma taxa aos catadores de $\mathrm{R} \$ 10,00$ (dez reais) ao mês para estarem vinculados a ela, com a suposta vantagem de oferecerem o melhor preço pelo material vendido, e ainda possibilitarem vales (adiantamentos) sobre valores a serem recebidos. Em ambas as Instituições o material era vendido para as empresas de reciclagem ao atingirem a quantidade necessária para a venda, o que só era possível através de um número de oito a doze catadores atuando diariamente, dependendo do material, e obtendo boas coletas (o que para eles significa "carrinho cheio"). Ao se vincularem nas Instituições, deveriam cumprir um regimento interno e assumir um compromisso com o grupo, que compreende as entregas dos materiais com exclusividade, além de obter coletas semanalmente, sem exigências fixas em relação 
às quantidades, em ambas as Instituições. A remuneração era feita conforme a produção, vinculada à quantidade de material que o catador entregava (de forma individual), por carrinho, com preço variando conforme o obtido pela venda dos materiais às empresas recicláveis. Eram comprados pelas Instituições "A" " "B" todos os tipos de materiais inorgânicos: latas, papéis, aço, papelão, plástico, entre outros. Ambas emprestavam um carrinho ao catador.

TABELA 1. Dados gerais das Instituições "A" e "B"

\begin{tabular}{|c|c|c|}
\hline INSTITUIÇÃO & A & B \\
\hline Tempo de funcionamento: & 3 anos & 2 anos \\
\hline $\mathrm{N}^{\mathrm{o}}$ catadores vinculados: & 33 & 28 \\
\hline Serviços gerais dos catadores: & $\begin{array}{l}\text { Fornecem local para a separação dos } \\
\text { materiais. }\end{array}$ & $\begin{array}{l}\text { Não fornecem locais para a separação, devem trazer } \\
\text { selecionados. }\end{array}$ \\
\hline Taxas cobradas aos catadores: & Sem taxas & Taxa de $\mathrm{R} \$ 10,00 /$ mês, pelo vínculo. \\
\hline Forma de pagamento dos materiais: & $\begin{array}{l}\text { Conforme revenda dos materiais, } \\
\text { pagamento semanal. }\end{array}$ & $\begin{array}{l}\text { Conforme revenda dos materiais, mas possibilitam } \\
\text { "vales". }\end{array}$ \\
\hline Pagamento do material: & Quando recebido da revenda & Quando recebido da revenda \\
\hline
\end{tabular}

\section{Dados gerais individuais e de moradia}

Dos 22 entrevistados $72,7 \%$ eram do gênero masculino $(n=16)$ e $27,3 \%$ do gênero feminino $(n=6)$. A média de idade foi de 39 anos (DP: 11,36), sendo analfabetos $(9,1 \%$, $\mathrm{n}=2)$ com primeiro grau incompleto $(68,2 \%, \mathrm{n}=15)$, e primeiro grau completo $(22,4 \%, \mathrm{n}=5)$. Dos entrevistados $68,2 \%(\mathrm{n}=15)$ trabalhavam mais de oito horas/dia de segunda à sábado, com renda mensal média obtida de R \$335,22 (DP: 158,23). Em relação ao estado civil: 45,5\% $(n=10)$ eram solteiros, $27,3 \%(n=6)$ moravam junto com companheiro (a), 22,7\% ( $\mathrm{n}=5)$ eram separados, e 4,5\% $(\mathrm{n}=1)$ viúvo. Moravam com mais de um filho com idade inferior a 14 anos, 22,7\% $(n=5)$ dos entrevistados.

A moradia era alugada para $50,0 \%(n=11)$ dos entrevistados, sendo em locais em geral de periferia. Moravam de favor em barracões $27,3 \%(\mathrm{n}=6)$, e em invasões $22,7 \%(n=5)$. Dos catadores entrevistados 86,4\% ( $=19)$ optou por esse trabalho pelo desemprego. Outros estudos também trouxeram a causa do desemprego como fator principal que os levaram a buscar nessa profissão uma forma de sobrevivência (FERREIRA, 2004; MEDEIROS; MACEDO, 2006).

\section{Caracterização do ambiente de trabalho e riscos}

$\mathrm{O}$ trabalho não tem um horário rígido para iniciar. $\mathrm{Na}$ Instituição "A" o catador deve buscar o carrinho no dia do trabalho, e na Instituição "B" o catador pode levá-lo até seu local de moradia. Os catadores saem pelas ruas da cidade, empurrando carrinhos manualmente em busca de materiais recicláveis e reaproveitáveis, pois não basta o material ser reciclável. Deslocam-se por regiões, muitas vezes passando por mesmas ruas em horários diferentes, existindo um trajeto em geral fixo, por se familiarizarem com os horários de retirada do lixo de condomínios e residências. Nas ruas estão sujeitos ao trânsito, ao pararem os carrinhos nas ruas, pois não conseguem andar com eles nas calçadas, pois muitas são irregulares em Curitiba, bloqueiam muitas vezes parcialmente uma das vias na rua, e estão expostos em alguns horários e locais aos engarrafamentos no trânsito que atrasam seu trabalho. Em determinados horários e vias, isso gera um transtorno tanto para o transeunte dirigindo seu carro, quanto para o trabalhador que não vê muitas vezes outra forma de se deslocar que não seja pelas ruas, que minimizam seus esforços físicos conforme a condição do chão que percorre. A falta de conforto para deslocar os carrinhos, poderia ser justificado pelo esforço físico exigido, que muitas vezes exige movimentos repetitivos de flexão e extensão do tronco ao empurrar o carrinho, e inclinações e rotações laterais do tronco para visualizar carros que passam; piorando o esforço físico quando o carrinho está cheio. Havendo ainda diferenças em níveis de força muscular exigida entre homens e mulheres, em função de altura, idade, massa corporal, entre outras, não investigados neste estudo.

Estão expostos às condições climáticas variáveis e comuns da cidade de Curitiba, onde temperaturas oscilam com freqüência entre quente e frio em um mesmo dia. Salienta-se aqui que o maior desconforto relatado esteve em relação à exposição ao sol e calor, sendo as observações ocorridas nos meses de novembro e dezembro.

As coletas nas ruas incluem aberturas de sacos de lixos na busca de materiais recicláveis, que na maioria das vezes não estavam separados em sacos próprios, salvo em alguns condomínios. Estão expostos aos riscos de acidente de trabalho, por contato com objetos pérfuro-cortantes nos 
lixos e não uso de Equipamento de Proteção Individual (E.P.I). Em síntese estão em exposição aos riscos ambientais físicos (iluminação, temperatura); químicos (poeiras, gases da poluição em grande centro e às vezes do próprio lixo); e biológicos (vírus, bactérias, fungos, parasitas e outros) pelo contato com o lixo.

\section{Processos de Trabalho nas Instituições}

Ambas as Instituições eram em galpões, sendo a Instituição " $A$ " maior que a "B" em relação ao espaço físico. $\mathrm{Na}$ Instituição "A" haviam balcões fixados ao chão onde os trabalhadores abriam os sacos de lixo para separação dos materiais, o que era reaproveitável era separado no próprio balcão, para serem preensados em máquinas. $\mathrm{O}$ que não era reaproveitável era colocado em latões de lixo. Algumas vezes houve necessidade de lavagem de alguns materiais, o que gerava ao mexer o lixo um desconforto para alguns catadores. Nem todas as pessoas (da sociedade) separam os lixos recicláveis, e alguns materiais reaproveitáveis são encontrados junto com papéis higiênicos utilizados, ou lixo orgânico já com odor desagradável. Depois de fazerem a separação levam junto à máquina de prensar, onde o material é preensado e pesado pelo responsável na vista do catador. Depois devem limpar o local (balcão) utilizado. $\mathrm{Na}$ Instituição "B" o catador já devia trazer separado o material de sua casa ou local de moradia, ou das ruas, que era também preensado e pesado pelo responsável; com a vantagem ou não, de não terem que executar esse serviço após um dia longo percorrido pelas ruas, e de não terem que limpar o local imediatamente após a utilização. Os valores dos pesos das coletas em ambas as Instituições eram anotados em fichas de papelão com os nomes dos catadores e dados pessoais, e repassavam o pagamento aos catadores após as revendas junto às empresas de reciclagem. Esse repasse depende diretamente da quantidade coletada pelos trabalhadores, portanto às vezes exigem quantidade de materiais coletados, como pode ser elucidado pela fala de um catador: "às vezes a gente tá cansado mas têm que trabalha..senão nóis não recebe, e eles ameçam cortá nóis..", com uma possibilidade de desligamento caso o trabalhador não seja para eles "eficiente".

$\mathrm{Na}$ Instituição " $\mathrm{A}$ " alguns trabalhadores referiram vantagens de moradia e refeição, em troca do trabalho, e ainda a perspectiva de poder realizar um trabalho honesto e não ter que roubar.

\section{Aspectos relacionados à saúde}

A prevalência de alguns sintomas obtidos, indicou sinais de sobrecargas no trabalho (físicas e mentais), além de outros sintomas que necessitariam de maiores investigações. A Tabela 2 demonstra os sinais/sintomas obtidos entre os entrevistados, com freqüência nos últimos 30 dias (resposta: frequentemente ocorre):

TABELA 2. Sintomas/sinais entre os catadores entrevistados

\begin{tabular}{lc}
\hline Sintomas/ Sinais & $\mathbf{n = 2 2}$ \\
\hline Dor músculo-esquelética & $90,9 \%(\mathrm{n}=20)$ \\
Cansaço físico & $95,5 \%(\mathrm{n}=21)$ \\
Dor de cabeça & $81,8 \%(\mathrm{n}=18)$ \\
Erupções cutâneas & $27,3 \%(\mathrm{n}=6)$ \\
Indigestão & $45,5 \%(\mathrm{n}=10)$ \\
Gastrite & $36,4 \%(\mathrm{n}=8)$ \\
Insônia & $27,3 \%(\mathrm{n}=6)$ \\
Dificuldade em se concentrar & $45,5 \%(\mathrm{n}=10)$ \\
Oscilação de humor & $63,6 \%(\mathrm{n}=14)$
\end{tabular}

$\mathrm{Na}$ Tabela 2, os sinais de maior prevalência entre os trabalhadores foram: dores músculo-esqueléticas, sendo a região mais afetada a região lombar; cansaço físico, dor de cabeça, oscilação de humor, indigestão e dificuldade de se concentrar; sendo que alguns trabalhadores relataram mais de um sinal/sintoma. Alguns sinais/ sintomas vão de encontro com alguns estudos, como o de Reinhold (1996) que encontrou manifestações de estresse de origem fisiológica como dor de cabeça, e de origem comportamental a insônia, entre outros. E Lipp (2007) cita como sintomas estressores na área emocional: depressão, desânimo, raiva, irritabilidade e ansiedade, entre outros. Em relação ao fato da dor lombar ter sido a região mais acometida, foi condizente com a maneira que o trabalho é realizado nas ruas e ao longo de jornadas que sobrepõe muitas vezes oito horas de trabalho. Como cita Granata e Marras (1995), e Marras (2000) que são fatores de risco para lombalgias, os movimentos repetitivos de inclinações e rotações do tronco.

Ainda entre os resultados, apresentaram baixa autoestima 59,1\% $(n=13)$ dos entrevistados, sendo mais evidente apesar de não significativamente no gênero feminino; das seis mulheres, cinco relataram baixa auto-estima. Desamparo foi relatado em $54,5 \%(n=12)$ dos entrevistados, com falas adicionais como: "a gente não tem apoio de ninguém...", ou ainda "fui preso, e agora não acho emprego...". Ansiedade foi relatada em $68,2 \%(\mathrm{n}=15)$ dos entrevistados, com falas adicionais: "a gente se preocupa pra saber o que vai conseguir no final do dia..precisamo ter o que come, fico preocupado $e$ às vezes não consigo nem dormir!"; e humilhação foi relatado entre $40,9 \%(n=9)$ dos entrevistados, sendo as falas adicionais: "é um trabalho humilhante..", ou ainda "às vezes tenho vergonha de catar, espero a pessoa passar pra poder catar...”. Há pouca valorização pelo trabalho expressa em algumas falas dos trabalhadores. Para Dejours et al. (1994) da mesma forma que o trabalho é estruturador, 
pode também ser patogênico ao ser humano. Para Dejours (1992) a insatisfação em relação ao significado do trabalho engendra um sofrimento cujo ponto de impacto é antes de tudo, mental. Em algumas falas dos catadores há relações com sofrimento social, enfatizando-se a importância do valor social do trabalho; que segundo Carreteiro (2003) abrange as dimensões: humilhação, falta de reconhecimento, vergonha. O catador de materiais recicláveis participa como elemento importante de um processo produtivo (reciclagem), mas não obtém o reconhecimento necessário, nem ganho suficiente pelo serviço prestado.

O medo também esteve presente em falas de catadores durante o trabalho: medo do trânsito: "parece que vão passar por cima da gente..."; medo da violência nas ruas: "tem catador que rouba da gente, é só a gente entrar no condomínio, se não tem ninguém olhando vem outro e tira as coisas do carrinho..e ameaça bate na gente!"; "o cara (motorista) xinga nóis, e ainda ameaça bater.."; medo pela insegurança do trabalho: "a gente não tem dia certo pra receber e precisamo do dinheiro prá comer...". O medo é uma característica do ser humano para se proteger e adotar estratégias de defesa contra constrangimentos físicos e psicológicos.

\section{CONCLUSÕES GERAIS}

O trabalho dos catadores é exaustivo, e com aspectos que podem colocar em risco a integridade física e mental do trabalhador; não se pretendeu neste estudo fazer aprofundamentos e sim levantamentos gerais. Foram encontrados entre os entrevistados sinais/ sintomas estressores e nas análises das atividades de trabalho, situações com características estressoras e percebidas como tal; e riscos principalmente de lesões músculo-esqueléticas em região lombar, e acidentes de trabalho (contato com objetos pérfurocortantes) decorrentes dos processos de trabalho.

Os resultados indicaram que há uma precarização nas condições de trabalho nas categorias: perfil sócio-demográfico, condições físicas, condições ambientais, medos e receios, e processos do trabalho. Entre os dados obtidos há evidências da necessidade de melhoria também na organização das classes, para que não existam "atravessadores". Apesar da Instituição " $\mathrm{A}$ " oferecer aparentemente melhores condições de trabalho, constatou-se em geral situações problemáticas, como: preços variados, incertezas quanto ao pagamento; não há também apoio institucional efetivo que os capacite e garanta sua segurança e saúde, o que dificulta também a questão da possibilidade efetiva de inclusão social (e não de uma aparente pseudo inclusão), apesar de não ser o foco desse estudo, sugere-se que direta ou indiretamente este fato pode afetar a saúde mental dos catadores. Políticas Públicas e incentivos municipais precisam ser reforçados. Há ainda necessidade de conscientização da população quanto à importância desse trabalho e de separar o lixo em suas casas, empresas, e em outros locais.

Pesquisas futuras devem aprofundar e investigar os aspectos abordados neste estudo e relacionados ao trabalho dos catadores.

ALENCAR, M. do C. B. de.; CARDOSO, C. C. O.; ANTUNES, M. C. Work conditions and health symptoms of ragickers in Curitiba. Rev. Ter. Ocup. Univ. São Paulo, v. 20, n. 1, p. 36-42, jan./abr. 2009.

\begin{abstract}
The objective of this research was to characterize the work conditions of the ragpickers and investigate symptoms related to worker's health, and with the job connected to institutions of materials collections in Curitiba city. The methodology consisted in two steps: selection of two institutions and interview of their owners, about the rag pickers' work, and selection of 22 ragpickers, eleven of each institution, for the tasks and activities analyses, based on Ergonomics (Guérin et al., 1994); application of a questionnaire consisted on demographic data, social-economic data, symptoms of health with week frequency in the last 30 days (based on UCU-Stress Model Questionnaire), and questions related about how they fell at work (anxious, helplessness, frustrated, and humiliation). The interviewers, $72.7 \%$ were masculine and $27.3 \%$ feminine. The results indicated a precarious work conditions in the categories: social-demografic profile, physical and physiological conditions, ambiental conditions, affairs and distrusts, organization and work processes. In the results were observed the presence of musculoskeletal disorder in $90.9 \%$ of the workers, and physical exhaustion in $95.5 \%$ of the interviewers. Other symptoms found: $81.8 \%$ of headaches, $27.3 \%$ of skin eruptions, $45.5 \%$ of indigestion, $63.6 \%$ of humor changes, $45,5 \%$ difficulty of concentration, $27.3 \%$ of insomnia, and others. Also were found: anxiety (68.2\%), helplessness (54.5\%), frustration $(59.1 \%)$, and humiliation $(40.9 \%)$ in the workers interviewed. The conclusion was that the work activity can affect the mental and the physical health, and public political structures are necessaries for a better work conditions.
\end{abstract}

KEY WORDS: Working conditions. Occupational health. Solid waste segregators. 


\section{REFERÊNCIAS}

1. CARRETEIRO, T. C. Sofrimentos sociais em debate. Psicologia USP, v. 14, p. 57-72, 2003.

2. CAMARGO, J. M; REIS, M. C. Desemprego: o custo da desinformação. Rev. Bras. Economia, v. 59, n. 3, p. 381425, 2006.

3. CBO - Classificação Brasileira de Ocupações. Disponível em: <http://www.mtecbo.gov.br>. Acesso em: ago. 2008.

4. CRUZ, R. M. Distúrbios musculoesqueléticos, processos de trabalho e cultura organizacional. In: TAMAYO, A. (Org.). Cultura e saúde nas organizações. Porto Alegre: Artmed, 2004.

5. DEJOURS, C.; ABDOUCHElli, E.; JAYET, C. Psicodinâmica do trabalho. São Paulo: Atlas, 1994.

6. DEJOURS, C. A loucura do trabalho. São Paulo: Cortez, 1992.

7. FERNANDES, J. D.; MELO, C. M. M.; GUSMÃO, M. C. C. M.; FERNANDES, J.; GUIMARÃES, A. Saúde mental e trabalho: significados e limites de modelos teóricos. Rev. Latinoamer. Enferm., v. 14, n. 5. Disponível em: http://www. eerp.usp.br/rlae. Acesso em jan. 2008.

8. FERREIRA, S. L. Os "catadores de lixo" na construção de uma nova cultura: a de separar o lixo e da consciência ambiental. Rev. Urutágua, n. 4, p. 1-6, 2004.

9. FERREIRA, J. A.; ANJOS, L. A. Aspectos de saúde coletiva e ocupacional associados à gestão dos resíduos sólidos municipais. Cad. Saúde Pública, v. 17, n. 3, p. 689-696, 2001.

10. GRANATA, K.; MARRAS, W. EMG-assisted modelo f biomechanical trunk loading during free-dynamic lifting. J. Biomech., v. 28, p.1309-1317, 1995.

11. GUÉRIN, F; LAVILle, A; DANiEllou, F; DURAFFOURG, J; KERGUELEN, A. Compreender o trabalho para transformá-lo: a prática da ergonomia. São Paulo: Ed. Edgard Blucher, 1997.

12. HELOANI, R.; LANCMAN, S. Psicodinâmica do trabalho: o método clínico de intervenção e investigação. Produção, v. 14, n. 3, p. 77-86, 2004.

13. LIPP, M. E. N. Stress: conceitos básicos. In: LIPP, M. E. N (Org). Pesquisas sobre stress no Brasil: saúde, ocupações e grupos de risco. São Paulo: Ed. Papirus, 1996.

14. LEAL, A. C.; JÚNIOR, A. T.; ALVES, N.; GONÇALVES, M. A.; DIBIEZO, E. P. A reinserção do lixo na sociedade do capital: uma contribuição ao atendimento do trabalho na captação e na reciclagem. Rev. Terra Livre, v. 18, n. 9, p. 177-190, 2006.

15. LOPES, J. R. "Exclusão social” e controle social: estratégias contemporâneas de redução da sujeiticidade. Psicol. Sociedade, v. 18, n. 2, p. 13-24, 2006.

16. MARRAS, W. S. Occupational low back disorder causation and control. Ergonomics, v. 43, n. 7, p. 880-902, 2000.

17. MEDEIROS, L. O. F. R.; MACÊDO, K. B. Catador de material reciclável: uma profissão para além da sobrevivência? Psicol. Sociedade, v. 18, n. 2, p. 62-71, 2006.

18. MORIN, E. M. Conference. In: $10^{\mathrm{TH}}$ WORLD CONGRESS ON HUMAN RESOURCES MANAGEMENT, Rio de Janeiro, Brazil, August, $20^{\text {th }}, 2004$.

19. PORTO, M. F. S.; JUNCÁ, D. C. M.; GONÇALVES, R. S.; FILHOTE, M. I. F. Lixo, trabalho e saúde: um estudo de caso com catadores em um aterro metropolitano no Rio de Janeiro, Brasil. Cad. Saúde Pública, v. 20, n. 6, p. 15031514, 2004.

20. REINHOLD, H.H. Stress ocupacional do professor. In: LIPP, M. E. N. (Org). Pesquisas sobre stress no Brasil: saúde, ocupações e grupos de risco. São Paulo: Ed. Papirus, 1996.

21. SILVA, M. C.; FASSA, A. G.; KRIEBEL, D. Minor psyquiatric disorders among brazilian ragpickers: a cross sectional study. Environ. Health, v. 5, p. 1-10, 2006.

22. UCU Model Stress Questionnaire. Disponível em: <www. ucu.org.uk>. Acesso em 05 jun. 2007.

23. VELLOSO, M. Os catadores de lixo e o processo de emancipação social. Cien. Saúde Coletiva, v. 10, p. 49-61, 2005.

24. WORLD HEALTH ORGANIZATION (WHO). Mental health and work: impact, issues and good practices. Geneva, 2000 . 